\title{
Gefäßpermeabilität und Oxygenierung gleichzeitig darstellen
}

Redaktion:

Josef Gulden
Die Blutgefäße maligner Tumoren weisen strukturelle und funktionelle Anomalien auf. Durch ihere erhöhte Permeabilität wird das Gewebe schlechter mit Sauerstoff und auch Medikamenten versorgt. Beides - Hypoxie und reduzierte Medikamentenspiegel - führen zur Therapieresistenz. Nun nutzten Kollegen eine spezielle kernspintomographische Methode, die „Overhauser"-verstärkte MRT, bei der die Hyperpolarisierung von Protonen verwendet werden kann, um mithilfe des sauerstoffsensitiven Kontrastmittels OX63 die Sauerstoffkonzentration und die mikrovaskuläre Permeabilität in Xenograft-Tumoren in Mäusen gleichzeitig zu messen. Sie konnten damit nachweisen, dass hypoxische Re- gionen in den Tumoren räumlich und zeitlich mit einer hohen Gefäßpermeabilität korrelieren. Die immunhistochemische Aufarbeitung der Tumoren zeigte ferner, dass Permeabilität und strukturelle Defekte der Gefäße miteinander korrelieren. Die Technik, so die Autoren, verspricht interessante Einblicke in die Art und Weise, wie sich die Funktion der Gefäße und die Oxygenierung des Gewebes unter Chemo-, Radio- oder antiangiogenetischer Therapie ändern.

Matsumoto $S$ et al. Simultaneous imaging of tumor oxygenation and microvascular permeability using Overhauser enhanced MRI. Proc Natl Acad Sci USA 2009; 106: 17898-903.

\section{Tumorgefäße (II) \\ Remodeling durch Plazenta-Wachstumsfaktor}

Ein interessanter Ansatz für die Tumortherapie ist das Remodeling der Tumorgefäße. AntiVEGF (Vaskuläre endotheliale Wachstumsfaktor)-Medikamente normalisieren die Tumorvaskulatur und können dadurch das Eindringen von synchron verabreichten Zytostatika in das Tumorgewebe erleichtern. Substanzen, die sich gegen Notch-Liganden und ihre Rezeptoren

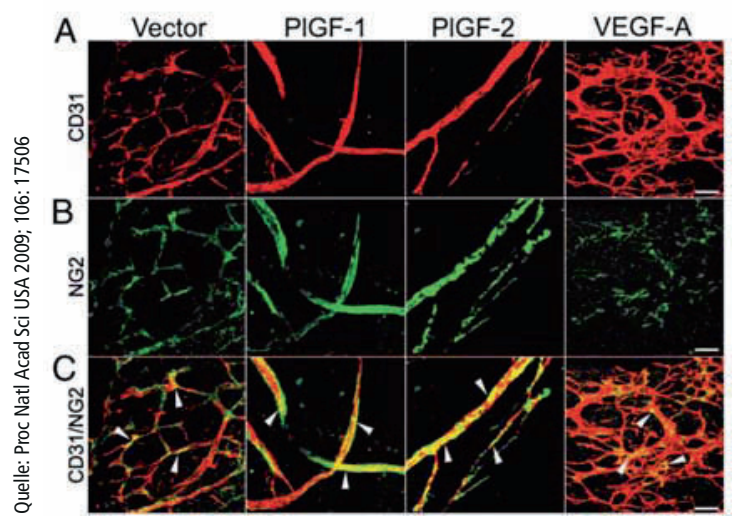

Abbildung 1. Gefäße von Tumoren, die mit einem leeren Vektor, bzw. mit Vektoren mit den Genen für PIGF-1, PIGF-2 und für VEGFA transfiziert wurden. Das CD31-Antigen markiert Gefäße allgemein, NG2 ist ein für Perizyten spezifisches Antigen. Die Pfeilspitzen deuten auf Perizyten hin, die auf den Gefäßen aufsitzen. Die Normalisierung des Gefäßsystems unter PIGF-Einfluss ist deutlich zu erkennen. richten, haben in präklinischen Studien durch Gefäßremodeling Anti-Tumor-Effekte gezeigt. Schwedische Zellbiologen konnten nun zeigen, dass auch von malignen Zellen abgesonderter Plazenta-Wachstumsfaktor (PlGF) auf die Tumorgefäße normalisierend wirkt:

PlGF führte zu einem Remodeling der Gefäße, die nicht nur größer und besser organisiert wurden, sondern auch normale Funktion und Permeabilität zeigten. Zugleich war das Tumorwachstum verglichen mit Tumoren, die etwa VEGF exprimierten, deutlich reduziert (Abb. 1). In einem Fibrosarkom und einem Bronchialkarzinom, die genetisch so modifiziert waren, dass sie PlGF-1 und PlGF-2 stabil exprimierten, waren die Dichte der Mikrogefäße und deren Verzweigung stark reduziert. Die Gefäße wiesen einen relativ großen Durchmesser auf und waren gut mit Perizyten bedeckt; diese Zellen fehlten dagegen auf der Oberfläche unbehandelter Tumoren. Auch in einem menschlichen Choriokarzinom, das spontan PlGF exprimiert, fanden die Autoren eine Normalisierung der Gefäße. PlGF könnte damit eine interessante Option in der Tumortherapie sein.

Hedlund EM et al. Malignant cell-derived PIGF promotes normalization and remodeling of the tumor vasculature. Proc Natl Acad Sci USA 2009; 106: 17505-10. 